\title{
Pengaruh Kepercayaan Dan Penerapan Teknologi Aplikasi Zakat Terhadap Minat Masyarakat Dalam Berzakat
}

\author{
Hani Fitria Rahmani, Wala Erpurini \\ Fakultas Ekonomi Universitas Nasional Pasim \\ Email authors: hanifr18@gmail.com ${ }^{1}$, wala_erpurini@yahoo.com ${ }^{2}$
}

\begin{abstract}
ABSTRAK
Saat ini penerapan teknologi penerimaan zakat berbasis aplikasi telah banyak berkembang di Indonesia namun kesadaran membayar zakat di kalangan masyarakat yang telah berpenghasilan yang seharusnya menjadi muzakki atau pemberi zakat masih belum berimbang dengan mustahik atau penerima zakat. Sedangkan, potensi zakat di Indonesia sangat besar menurut Sekretaris Jendral Kementrian Agama Nur Syam mencapai 217 Triliun pada tahun 2018 (Sumber: bisnis.com), sedangkan dana zakat yang terhimpun pada tahun 2018 sebesar Rp. 203 Miliar (Sumber: antaranews.com). Metode yang digunakan dalam penelitian ini adalah studi literatur, observasi, dan kuesioner. Kuesioner disebar dan data yang terkumpul 148 sampel dari populasi 3 wilayah besar di Indonesia yaitu Dki Jakarta dan Banten, Jawa Barat, serta Jawa Timur dengan metode penarikan sampel menggunakan metode Cluster Sampling. Uji analisis dalam penelitian ini dengan menggunakan path analysis. Secara parsial masing-masing varibel memiliki hubungan dan pengaruh, namun dalam penelitian ini variabel penerapan teknologi berpengaruh paling besar terhadap minat masyarakat dalam berzakat, hal ini sejalan dengan penelitian yang di lakukan oleh Winda, et al (2018) yang menyatakan, secara konseptual peran teknologi internet dalam pengumpulan dana zakat dari muzakki, akan memperluas daya jangkau amil dalam mengakses muzakki, begitu juga sebaliknya dengan teknologi internet muzakki akan lebih mudah menyalurkan zakatnya kepada amil.
\end{abstract}

Kata Kunci: Kepercayaan, Penerapan Teknologi, Teknologi Aplikasi, Minat, Zakat

\section{PENDAHULUAN}

Indonesia merupakan salah satu negara dengan populasi muslim terbesar di dunia. Sengai bangsa yang majemuk Indonesia merupakan negara yang memiliki keanekaragaman mulai dari suku, budaya, adat istiadat, Bahasa, dan agama. Di dalam Pancasila dan Undan-Undang Dasar 1945 menyatakan bahwa Indonesia bukanlah negara berdasarkan pada agama tertentu. Namun demikian, negara ikut terlibat aktif mengatur urusan umat Islam dan menjadikan ajaran Islam menjadi komponen penting dalam penyusunan peraturan perundang-undangan. Salah satunya adalah urusan zakat dengan amandemen Undang-Undang Nomor 38 tahun 1999 menjadi Undang-Undang Nomor 23 tahun 2011 tentang pengelolaan zakat.

Pada saat ini, masyarakat Indonesia yang umumnya penduduk muslim sekarang mulai sadar akan zakat oleh sebab itu di butuhkan peran pemerintah atau negara dalam mengawal dan melaksanakan isi Undang-Undang zakat agar para Muzakki atau orang berzakat tidak ragu pada Lembaga pemerintah dalam 
mengelola zakat. Lembaga atau badan yang mengelola zakat harus memberikan bukti nyata dari hasil para pemberi zakat dalam hal transparansi pengelolaan zakat agar bisa menarik para calon pemberi zakat baru khususnya kaum milenial untuk mengeluarkan zakat berdasarkan tingkat kepercayaan dan kemudahan akses teknologi dalam berzakat yang berkembang saat ini.

\section{Permasalahan}

Saat ini penerapan teknologi penerimaan zakat berbasis aplikasi telah banyak berkembang di Indonesia namun kesadaran membayar zakat di kalangan masyarakat yang telah berpenghasilan yang seharusnya menjadi muzakki atau pemberi zakat masih belum berimbang dengan mustahik atau penerima zakat. Sedangkan, potensi zakat di Indonesia sangat besar menurut Sekretaris Jendral Kementrian Agama Nur Syam mencapai 217 Triliun pada tahun 2018 (Sumber: bisnis.com), sedangkan dana zakat yang terhimpun pada tahun 2018 sebesar Rp. 203 Miliar (Sumber: antaranews.com).

Dalam membayar zakat salah satu faktor yang mendorong adalah tingkat keyakinan sesuai dengan kepercayaan akan aturan agama Islam dimana dalam hadist HR. Bukhari menyebutkan "Sampaikan bahwa Allah SWT telah mewajibkan zakat kepada harta benda mereka, yang di pungut dari orang-orang kaya dan diberikan kepada orang-orang miskin diantara mereka."

Disamping itu, perkembangan teknologi informasi turut berperan dalam menentukan keputusan seseorang untuk berzakat berdasarkan kemudahan akses membeayar zakat secara online. Berikut adalah Lembaga zakat yang telah menggunakan aplikasi zakat berbasis online:

\begin{tabular}{lll}
\hline No & Lembaga Zakat & NamaAplikasi Zakat \\
\hline 1 & Rumah Zakat & Zakat Mobile By Rumah \\
& & Zakat \\
2 & DompetDuafa & www.dompetdhuafa.org \\
3 & BadanAmil Zakat Nasional & www.baznas.go.id \\
\hline \multicolumn{3}{c}{ Sumber : Data Di Olah Penulis }
\end{tabular}

\section{TujuanKhusus}

Dari uraian di atas dalam penghimpunan zakat di Indonesia saat ini belum maksimal terlihat dari selisih antara potensi dengan besarnya jumlah dana yang terhimpun. Oleh karenanya keberhasilan menghimpun dan mengelola dana zakat di Indonesia memiliki peran yang sangat besar bagi pemerataan kesejahteraan masyarakat khususnya umat Islam di Indonesia.

Penelitian ini bertujuan menggambarkan seberapa besar minat masyarakat untuk membayar zakat berdasarkan tingkat kepercayaan dan kemudahan akses 
teknologi dari lembaga zakat diIndonesia, yang pada akhirnya nilai penghimpunan zakat di Indonesia meningkat yang berdampak pada kesejahteraan umat.

\section{TINJAUAN PUSTAKA}

Dalam M. Yunus (2016) berdasarkan mazhab Syafi'I, zakat didefinisikan sebagai kadar yang ditentukan dari pada beberapa jenis harta, yang wajib dikeluarkan kepada golongan manusia tertentu apabila cukup syarat tertentu. Para fuqaha" mazhab Maliki mendefinisikan zakat sebagai mengeluarkan sebahagian yang khusus daripada harta yang khusus yang telah mencapai had kuantiti yang mewajibkan zakat kepada orang yang berhak menerimanya (mustahiq) dengan syarat pemilikan itu penuh dan mencapai hawl (setahun), bukan bertambah barang dan bukan pertanian. Pengelolaan zakat menurut Undang-Undang No. 38 Tahun 1999 adalah sebuah kegiatan perencanaan, pengorganisasian, pelaksanaan, pengawasan terhadap pengumpulan dan pendistribusian serta pendayagunaan zakat. Keberadaan organisasi pengelola zakat di Indonesia telah diatur dalam perundang-undangan, yakni UU No. 38 Tahun 1999 tentang Pengelolaan Zakat, Keputusan Menteri Agama No. 581 Tahun 1999 tentang Pelaksanaan UU No. 38 Tahun 1999 dan Keputusan Direktur Jenderal Bimbingan Masyarakat Islam dan Urusan Haji No. D/291 Tahun 2000 tentang Pedoman Teknis Pengelolaan Zakat. Peraturan bertujuan agar organisasi pengelola zakat dapat lebih profesional, amanah dan transparan sehingga dana yang dikelola dapat berdampak positif terhadap pemberdayaan dan kesejahteraan umat.

Berdasarkan penelitian Abu Bakar (2010) yang berjudul motivasi membayar zakat penghasilan untuk studi di Malaysia, faktor utama yang memengaruhi membayar zakat penghasilan adalah keyakinan bahwa zakat merupakan kewajiban umat Islam. Kemudian percaya dalam bagian harta yang dimiliki ada hak orang miskin yang membutuhkan, serta keyakinan dengan membayar zakat dapat memperbaiki kondisi ekonomi orang miskin. Dalam penelitian Ma'fiyah (2018) mengemukakan Faktor dalam perspektif individu yang mempengaruhi muzakki membayar zakat ke lembaga zakat formal adalah berkaitan dengan kesadaran dan kepercayaan, dengan variabel indikator dengan nilai rata-rat tertinggi adalah ingin membantu orang-orang yang membutuhkan/mustahik, ingin mendapatkan ridho Allah, ingin membersihkan harta.

Selain itu menurut Winda, et al (2018) Secara konseptual peran teknologi internet dalam pengumpulan dana zakat dari muzakki, akan memperluas daya jangkau amil dalam mengakses muzakki, begitu juga sebaliknya dengan teknologi internet muzakki akan lebih mudah menyalurkan zakatnya kepada amil. Dan beberapa peneliti (Halimatusa'diyah, 2015; Latief, 2010; Müller, 2017) dalam Dewi (2018) menyebutkan ada dua faktor utama yaitu faktor penarik dan faktor pendukung. Faktor penarik yaitu semangat menyadarkan umat, semangat melayani 
secara profesional, semangat berinovasi membantu mustahiq, dan semangat memberdayakan masyarakat. Adapun faktor pendorong adalah potensi penghimpunan dana zakat yang besar, regulasi yang mendukung, infrastuktur Teknologi Informasi (TI) yang mendukung, dan tingkat kesadaran masyarakat yang makin meningkat.

Adapun variabel terikat yang dalam penelitian ini adalah minat muzakki dalam hal ini masyarakat. Minat menurut Bimo. W dalam Azy Athoillah (2017) adalah suatu keadaan dimana seseorang mempunyai perhatian terhadap sesuatu dan disertai keinginan untuk mengetahui dan mempelajari maupun membuktikan.

Faktor-faktor yang mendasari minat menurut Z. Kasijan dalam Azy Athoillah (2017) yaitu faktor dorongan dari dalam, faktor dorongan yang bersifat sosial dan faktor yang berhubungan dengan emosional. Faktor dari dalam dapat berupa kebutuhan yang berhubungan dengan jasmani dan kejiwaan. Timbulnya minat dari diri seseorang juga dapat didorong oleh adanya motivasi sosial yaitu mendapatkan pengakuan dan penghargaan dari lingkungan masyarakat dimana seseorang berada.15 Minat didefinisi operasionalkan sebagai kecenderungan yang menetap pada diri Muzakki atau masyarakatuntuk menyalurkan zakat.

\section{METODE PENELITIAN}

Adapun alat metode yang digunakan dalam penelitian ini :

1. Studi literatur, yaitupengumpulan data dengancaramempelajaribuku, makalah, majalah ilmiah, guna memperoleh informasi yang berhubungan dengan teoriteori dan konsep-konsep yang berkaitan dengan masalah dan variabel yang diteliti yang terdiri kepercayaan, teknologi informasi dan minat berzakat.

2. Observasi, dilakukain dengan mengamati langsung objek yang berhubungan dengan masalah yang diteliti khususnya mengenai kepercayaan dan teknologi informasi pada zakat.

3. Kuesioner, dilakukan dengan menyebarkan seperangkat daftar pertanyaan tertulis kepada responden (sampel penelitian). Responden tinggal memilih alternatif jawaban yang telah disediakan pada masing-masing alternatif jawaban yang dianggap paling tepat. Dalam kuesioner ini penulis mengemukakan beberapa pertanyaan yang mencerminkan pengukuran indikator dan variabel (X1) kepercayaan, variabel (X2) teknologi informasi, dan variabel (Y) minat masyarakat dalam berzakat. Kuisioner ini ditujukan kepada umat muslim di Jawa Barat.

Pada saat melakukan penyebaran kuesioner dilakukan pengumpulan data dan sampling. Data yang terkumpul 148 sampel dari populasi 3 wilayah besar di Indonesia yaitu Dki Jakarta dan banten, Jawa Barat, serta Jawa Timur dengan metode penarikan sampel menggunakan metode Cluster Sampling. Cluster 
Sampling merupakan cara pengambilan sampel yang berdasarkan pada clustercluster tertentu (Sugiyono, 2003:74-78). Menurut Cohen, et.al (2007:101) semakin besar sampel dari besarnya populasi yang ada akan semakin baik. Senada dengan pendapat tersebut Roscoe dalam Sugiyono (2012:91) menyatakan tentang ukuran sampel untuk penelitian yaitu ukuran sampel yang layak dalam penelitian adalah antara 30 sampai dengan 500. Populasi dalam penelitian ini adalah muzakki, yaitu para pemberi zakat yang jumlahnya tidak diketahui dan dapat dikatakan dalam kategori tidak terhingga.

Teknik pengambilan sampel menggunakan teknik non probability yakni teknik sampling insendental, yakni teknik penentuan sampel berdasarkan kebetulan, yaitu siapa saja secara kebetulan/insindetal bertemu dengan peneliti dapat digunakan sebagai sampel, bila dipandang orang yang kebetulan di temui cocok sebagai sumber data (Sugiono, 2012:56). Jumlah sampel yang diambil dalam penelitian ini menggunakan rumus Lemeshow (1997:2), hal ini dikarenakan jumlah populasi tidah diketahui atau tidak terhingga

TEMUAN DAN PEMBAHASAN

\section{Hasil Pengolahan Data}

Tabel 1. Matriks korelasi antar variabel

\begin{tabular}{|l|r|r|r|}
\hline \multicolumn{4}{|c|}{ Corelation } \\
\hline & X1 & \multicolumn{1}{|c|}{ X2 } & \multicolumn{1}{|l|}{ Y } \\
\hline X1 Pearson Corelation & 1 & .562 & .454 \\
\hline X2 Pearson Corelation & .562 & 1 & .596 \\
\hline Y Pearson Corelation & .454 & .596 & 1 \\
\hline
\end{tabular}

Sumber: Pengolahan Data SPSS 2020

Dari tabel 4.1 dapat diketahui bahwa koefisien korelasi terbesar antara variabel X1 dan X2 terhadap Y diperoleh dengan nilai .562. jika angka tersebut diinterpretasikan kedalam tabel pedoman untuk memberikan interpretasi koefisien korelasi (Sugiono, 2005:183) maka angka tersebut menunjukan tingkat hubungan yang sedang antara kepercayaan dan penerapan teknologi terhadap minat dalam berzakat.

Hal tersebut menunjukan bahwa terdapat hubungan yang signifikan antara kepercayaan dan penerapan teknologi terhadap minat dalam berzakat. Adapun nilai koefisien korelasi terbesar antar variabel yang dimiliki oleh variabel penerapan teknologi sebesar .596. Dengan demikian penerapan teknologi merupakan variabel yang dominan dalam mempengaruhi minat masyarakat dalam berzakat. 


\section{Menghitung Taksiran Koefisien Jalur}

$\mathrm{P}_{\mathrm{yxj}}=\mathrm{R}^{-1} \mathrm{R}_{\mathrm{yx}}$

$\left[\begin{array}{l}P_{y x 1} \\ P_{y x 2}\end{array}\right]=\left[\begin{array}{ll}r_{x 1 x 1} & r_{x 1 x 2} \\ & r_{x 2 x 2}\end{array}\right]^{-1}\left[\begin{array}{l}r_{y x 1} \\ r_{y x 2}\end{array}\right]$

NilaiKoefisienJalur

$$
\left[\begin{array}{l}
P_{y x 1} \\
P_{y x 2}
\end{array}\right]=\left[\begin{array}{c}
0,174 \\
0,498
\end{array}\right]
$$

Menghitung $R_{y\left(X 1 X_{2}\right)}^{2}$ (koefisiendeterminasi)

$$
\begin{aligned}
& R_{y(X 1 X 2)}^{2}=\left[\begin{array}{ll}
P_{y x 1} & P_{y x 2}
\end{array}\right]\left[\begin{array}{l}
r_{y x 1} \\
r_{y x 2}
\end{array}\right] \\
& R_{y(X 1 X 2)}^{2}=0,375
\end{aligned}
$$

Pengaruh variabel lain yang tidak dimasukkan kedalam model. $\left(P_{y \varepsilon}\right)$

Perhitungan $P_{y \varepsilon}$

$\mathrm{P}_{Y_{\varepsilon}}=1-R^{2}{ }_{y(X 1 X 2)}$

$P_{Y \varepsilon}=1-0,375=0,625$

Koefisien Determinasi $=\mathrm{R}^{2} \times 100 \%$

$$
=0,375 \times 100 \%=37,5 \%
$$

Tabel 2. Besarnya Koefisien Jalur

\begin{tabular}{||c||c||}
\hline \multirow{2}{*}{ KoefisienJalur } & $\rho_{y x 1}=0,174$ \\
\cline { 2 - 2 } & $\rho_{y x 2}=0,498$ \\
\hline \hline Pengaruhsecarabersamaan & $\mathbf{0 , 3 7 5}$ \\
\hline \hline Pengaruhkoefisienresidu & $\mathbf{0 , 6 2 5}$ \\
\hline
\end{tabular}

Sumber : Pengolahan Data SPSS 2020

Dari hasil pengolahan data di atas, maka dapat digambarkan diagram sebagai berikut: 


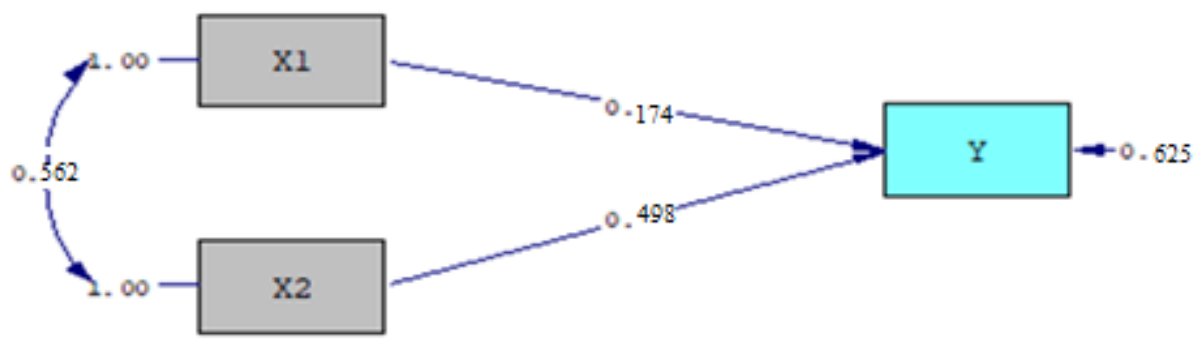

Chi-Square $=0.00, d f=0, P-v a l u e=1.00000, \quad$ RMSEA $=0.000$

Keterangan :

GAMBAR 1. Diagram jalur pengujian hipotesis

X1 = Kepercayaan

$\mathrm{X} 2$ = Penerapan teknologi

$\mathrm{Y}=$ Minat dalam berzakat

\section{PEMBAHASAN}

\section{Pengujian Secara Individu}

Karena hasil pengujian secara keseluruhan memberikan hasil yang signifikan, maka untuk mengetahui variable bebas mana yang berpengaruh nyata terhadap $Y$ dapat dilanjutkan dengan pengujian secara individual.

$\mathrm{Ho}=\mathrm{P}_{\mathrm{xixj}} \leq 0 \quad$ Tidak terdapat pengaruh yang nyata variable bebas yang ke-I $\left(X_{i}\right)$ terhadap $Y$

$\mathrm{H}_{1}=\mathrm{P}_{\mathrm{xixj}}>0 \quad$ Terdapat pengaruh yang nyata variable bebas yang ke-I $\left(X_{i}\right)$ terhadap $Y$

Statistic uji yang digunakan adalah:

$$
t_{i}=\frac{P_{y x i}}{\sqrt{\frac{\left(1-R^{2}\right) C R_{i i}}{n-k-1}}}
$$

Kriteria uji:

Tolak Ho jika t hitung $>\mathrm{t}$ table $\left(t_{\alpha ; n-k-1}\right)$ atau jika $-\mathrm{t}$ hitung $<-\mathrm{t}$ tabel

Hasil perhitungan dapat kita lihat pada table berikut ini:

Tabel 3. Pengujian Individual

\begin{tabular}{|c|c|c|l|c|c|}
\hline No & Hipotesis & Koefisienjalur & t hitung & $t$ tabel & kesimpulan \\
\hline 1 & $\rho_{y x 1}>0$ & $\rho_{y x 1}=0,174$ & 2,191 & \multirow{3}{*}{1,977} & Ho ditolak \\
\cline { 2 - 4 } \cline { 5 - 6 } & $\rho_{y x 2}>0$ & $\rho_{y x 2}=0,498$ & 6,276 & & Ho ditolak \\
\hline
\end{tabular}

Sumber : Pengolahan data SPSS 2020 
Dari tabel di atas dapat kita ketahui bahwa nilai t hitung untuk Kepercayaan (X1) dan Penerapan teknologi (X2) lebih besar dari \pm 1,977 hal ini mengindikasikan bahwa faktor Kepercayaan (X1)dan Penerapan teknologi (X2) memberikan pengaruh yang signifikan terhadap variabel Minat dalam berzakat.

Maka diagram jalur berdasarkan pengolahan data yang dilakukan menggunakan software Spss v.25 untuk model analisis jalur Kepercayaan dan Penerapanteknologi dengan Minat dalam berzakat dapat diperoleh output yang digambarkan sebagai berikut:

Besarnya koefisien jalur kepercayaan $\left(\mathrm{X}_{1}\right)$ adalah 0,174 dengan $t$ hitung $>t$ tabel yaitu $8,726>1,984$ sehingga $H_{0}$ ditolak, menunjukan variabel kepercayaan $\left(\mathrm{X}_{1}\right)$ berpengaruh terhadap proses minat dalam berzakat. Secara langsung dan tidak langsung variabel kepercayaan $\left(X_{1}\right)$ berpengaruh sebesar 0.64 atau 6,4\%. Dalam penelitian ini kepercayaan merupakan variabel yang dominan mempengaruhi minat masyarakat dalam berzakat.

Sedangkan besarnya koefisien jalur Penerapan teknologi $\left(X_{2}\right)$ adalah0,498 dengan $\mathrm{t}$ hitung $>\mathrm{t}$ tabel yaitu 6,697 $>1$,984 sehingga $\mathrm{H}_{0}$ ditolak, menunjukan variabel penerapan teknologi $\left(X_{2}\right)$ berpengaruh terhadap proses minat masyarakat dalam berzakat. Secara langsung dan tidak langsung variabel penerapan teknologi $\left(\mathrm{X}_{2}\right)$ berpengaruh sebesar 0.281 atau $28,1 \%$.

\section{Pengujian Keseluruhan}

Hipotesis utama penelitian ini adalah Kepercayaan dan Penerapan teknologi berpengaruh terhadap Minat dalam berzakat. Hipotesis penelitian tersebut dinyatakan dalam hipotesa statistik berikut ini:

$\mathrm{H}_{0}: \rho_{y x 1}=\rho_{y x 2}=0$

$\mathrm{H}_{1}$ : sekurang-kurangnya ada sebuah $\rho_{y x i} \neq 0, ; \mathrm{i}=1,2$

Statistik uji yang digunakan adalah:

$$
F=\frac{(n-k-1) R_{Y(X 1 X 2)}^{2}}{k\left(1-R_{Y(X 1 X 2)}^{2}\right)}
$$

Kriteria uji, tolak Ho jika $\mathrm{F}$ hitung $>F_{\alpha}\left(\mathrm{k}_{\mathrm{in}} \mathrm{k}-1\right)$, dengan $F_{\alpha}\left(\mathrm{k}_{\mathrm{in}} \mathrm{-k}-1\right)$ diperoleh dari tabel distribusi $\mathrm{F}$ dengan $\alpha=5 \%$ dan derajat bebas $\mathrm{db}_{1}=\mathrm{k}$, dan $\mathrm{db}_{2}=\mathrm{n}-\mathrm{k}-1$

Tabel 4.4

Pengujian Secara Simultan

\begin{tabular}{||c|c|c|c||}
\hline HipotesisAlternatif & F hitung & F tabel & Kesimpulan \\
\hline $\begin{array}{c}\text { (X1, X2) } \\
\text { secarasimultanberpengaruhterhadap } \\
\text { Y }\end{array}$ & 43,573 & 3,06 & Signifikan \\
\hline
\end{tabular}

Sumber : Pengolahan data SPSS 2020 
Pada tabel di atas dapat kita ketahui bahwa hasil pengujian signifikan yang berarti secara simultan Kepercayaan (X1) dan Penerapan teknologi (X2) memberikan pengaruh yang nyata terhadap Minat dalam berzakat(Y). Hasil uji pengaruh secara bersama-sama variabel bebas $(\mathrm{X} 1$ \& X2) terhadap variabel Dependen (Y) menunjukan nilai $\mathrm{F}$ hitung $(43,573)$ dengan signifikansi (derajat/kesalahan alpha/ $\alpha$ sebesar 0,000 (0,00\%) lebih kecil (<) dari 5\% (kesalahan yang diperbolehkan). Artinya Variabel bebas yang diteliti secara bersama-sama berpengaruh terhadap Minat dalam berzakat (Y).

\section{KESIMPULAN DAN SARAN}

Secara parsial masing-masing varibel memiliki hubungan dan pengaruh, namun dalam penelitian ini variabel penerapan teknologi berpengaruh paling besar terhadap minat masyarakat dalam berzakat, hal ini sejalan dengan penelitian yang di lakukan oleh Winda, et al (2018) yang menyatakan, secara konseptual peran teknologi internet dalam pengumpulan dana zakat dari muzakki, akan memperluas daya jangkau amil dalam mengakses muzakki, begitu juga sebaliknya dengan teknologi internet muzakki akan lebih mudah menyalurkan zakatnya kepada amil. Oleh karenanya dalam pengelolaan zakat di Indonesia harus mengadaptasi cara dalam menghimpun zakat dengan menerapkan sistem informasi berbasis teknologi. Dimana hal ini menjadi faktor penunjang serta memberikan kemudahan bagi muzzaki untuk menyalurkan kewaiban zakatnya.

\section{DAFTAR PUSTAKA}

Abu Bakar, NurBarizah A, Hafiz Majdi Abdul Rashid. (2010). Motivations of Paying Zakat on Income: Evidence from Malaysia. International Journal of Economics and Finance Vol. 2, No. 3.

Azy Athoillah Yazid. (2017). Faktor-Faktor Yang Mempenagruhi Minat Muzakki Dalam Menunaikan Zakat Di Nurul Hayat Cabang Jember. Economic: JurnalEkonomidanHukum Islam, Vol.8, No. 2

Cohen, L., Manion, L., \& Morrison, K. 2007.Research Methods in Education (6thed.). London, New York: Routllege Falmer

Dewi. S, Christina. T. S. (2018). Efektivitas Tata Kelola Dana Zakat. Jurnal Akuntansi Multiparadigma JAMAL Volume 9 Nomor 2 Halaman 346-364

Halimatusa'diyah, I. (2015). Zakat and SociHalimatusa'diyah, I. (2015). Zakat and Soci al Protection: The Relationship BetweenSocioSocioSocioment in Indonesia. Journal of Civil Society, 11(1), 79(1), 79(1), 79080/17448689.2015.1019181

https://kabar24.bisnis.com/read/20180419/15/786593/kemenag-potensi-zakatindonesia-capai-rp217-t= 
https://www.antaranews.com/berita/782108/penghimpunan-zakat-baznas-naik-318persen-selama-2018

Latief, H. (2010). Health Provision for the Poor Islamic Aid and the Rise of Charitable Clinics in Indonesia. South East Asia Research, 18(3), 503(3), 503(3), 503

Ma'fiyah, Sheila Ardilla Y, Taufik A. 2018. PreferensiMuzakkiDalamMemilihMembayar Zakat di Lembaga Zakat Formal. Al Falah: Journal of Islamic Economics, Vol. 3, No. 2, 2018.

Muhammad Yunus. 2016. Analisis Pengaruh Kepercayaan, Religiusitas Dan Kontribusi Terhadap Minat Pedagang Mengeluarkan Zakat Di Baitul Mal (Studi Kasus Pada Pedagang Pasar Los Lhokseumawe). At-Tawassuth, Vol. 1, No. 1, 2016: 95-124

Müller, D. M. (2017). From Consultancy to Critique: The 'Success Story' of Globalized Zakat Management in Malaysia and its Normative Ambiguities. Globalizations, 14(1), 81izations, 14(1), 81izations, 14(1), 8110.1080/14747731.2016.1200309

Sugiyono. (2003). Metode Penelitian Bisnis. Bandung. Pusat Bahasa Depdiknas.

Sugiyono. 2005. Memahami Penelitian Kualitatif. Bandung: CV. Alfabeta.

Sugiyono. (2012). Memahami Penelitian Kualitatif". Bandung : Alfabeta.

Stanley Lemeshow, David W. Hosmer J, Janeile Klar \& Stephen K. Lwanga, 1997,Besar Sampel dalam Penelitian Kesehatan, Gajah Mada Uneversity Press, Yokyakarta

Winda Afriyenis, Anita Ade rahma, FebriAldi. 2018. Implementasi Teknologi Informasi Dan Komunikasi Dalam Zakat Untuk Meningkatkan Kesejahteraan Masyarakat Miskin. JEBI (Jurnal Ekonomi dan Bisnis Islam) - Volume 3, Nomor 2, Juli-Desember 2018 